\title{
Study of Overvoltage Protection and Insulation Coordination for MMC based HVDC
}

\author{
Yilei Gu, Xiaoming Huang, Peng Qiu, Wen Hua \\ Power Grid Technology Center \\ Z(P)EPC Electric Power Research Institute \\ Hangzhou, P. R. China \\ guyilei21@163.com
}

\author{
Zheren Zhang, Zheng Xu \\ Department of Electrical Engineering \\ Zhejiang University \\ Hangzhou, P. R. China \\ 3071001296zhang@zju.edu.cn
}

\begin{abstract}
This paper focus on overvoltage protection and insulation coordination in Modular Multilevel Converter based HVDC system planning. An overvoltage protection scheme, which bases on the topology used in Transbay project by Siemens, is proposed in this paper. The scheme draws from the characteristics of MMC-HVDC systems and the research results in classic HVDC systems, by placing arresters at some key locations in the MMC-HVDC converter station. With this scheme, the overvoltage at those key points can be limited to an acceptable range and hence protect the key equipment concerned. Since all the DC lines of the project are undersea cables, no lighting overvoltage is considered and 14 faults which could happen are carefully selected to serve as the verification conditions for the insulation design. Based on the PSCAD/EMTDC simulations and the deterministic method, the specified withstand voltage levels of the critical equipment in the converter station is calculated.
\end{abstract}

Keywords-Modular Multilevel Converter; Station Faults; Overvoltage; Arrester Configuration; Insulation Coordination

\section{INTRODUCTION}

As a newly introduced topology of voltage-source converter (VSC), multilevel modular converter (MMC) is particularly suitable for applications of HVDC power transmission in the island, urban distribution, connecting new energy to grid and so on. Based on cascaded connection of chopper-cells per leg, MMCs require low consistent dynamic trigger voltage evenness; have a good scalability, low total harmonic distortion, low switching frequency, and low operating loss ${ }^{[1,2]}$. Till now, the Transbay project ${ }^{[3]}$ and Shanghai Nanhui demonstration project ${ }^{[4]}$ have been put into operation. In addition, there are more projects in preparation or being scheduled at home and abroad, such as the Inelfe Project which connects Spain and France, the Dalian cross-sea MMC-HVDC (MMC based HVDC) demonstration project at Liaoning, the Zhoushan multi-terminal MMC-HVDC demonstration project at Zhejiang, the Nan'ao multi-terminal HVDC Transmission System at Guangdong.

For MMC-HVDC system planning, overvoltage protection and insulation co-ordination are critical issues that arise inevitably and must to be solved. If the withstand voltage of equipment in MMC-HVDC system is chosen to be too high, difficulties in the manufacture of converter equipment will increase accordingly, and so does the total cost of the MMC-HVDC system; If the withstand voltage of equipment in MMC-HVDC system is chosen to be too low, the failure probability because of malfunction and fault will consequentially increase, causing unnecessary economic losses in return. Thus, to select a proper insulation co-ordination scheme is an important part in the entire cycle of MMC-HVDC planning. In recent years, researches on MMCs have been deeper and wider, but mostly on mathematical modeling and analyzing, controller designing, modulation strategy, redundancy protection ${ }^{[5-9]}$, etc. In the same time, there're few researches on overvoltage protection and insulation co-ordination of MMC-HVDC.

For the lack of researches on overvoltage protection and insulation co-ordination, this paper proposes an overvoltage protection scheme for MMC-HVDC. Based on classic HVDC and existed research results of MMC-HVDC, the protection scheme is to place arresters at some key locations in the MMC-HVDC converter stations to limit overvoltage at these points to an acceptable range, thus directly protecting the critical equipment. A simulation is conducted by using PSCAD/EMTDC, to calculate the overvoltage and then the specified withstand voltage of a certain MMC-HVDC system.

\section{TOPOLOGY OF MMC AND THE OVERVOLTAGE TO BE CONSIDERED}

\section{A. Basic Topology Of MMC}

Till now, some basic topologies of MMC have been proposed, but the topology that has been put into practice in actual project is mainly the one that SIEMENS used in the Transbay project. In this topology, the converter station is grounded through star-shaped inductance grounding equipment in the AC side, as shown in fig.1. compared with other topologies, this one has the following characteristics: technical maturity is higher, and the planners could fully learn from the experience of the existing domestic and foreign projects; structure is simple, as only one converter transformer is needed in each converter station thus shrinks the foot-print; no DC offset in the converter transformer, even regular transformers can be used in alternative, and equipment cost is much lower.

\section{B. Overvoltages and faults in the MMC-HVDC system}

According to duration time, overvoltage occurred in MMC-HVDC converter station can be specified as temporary overvoltage, switching overvoltage and lightning overvoltage. As the system under research uses under-sea cables as DC lines, the lightning overvoltage is neglected in 
this paper. For temporary overvoltage, surge arresters (even the multi-column arresters) can't totally absorb all the tremendous amount of energy, because of its long duration time. As a result, it's not recommended to use arrester alone to limit the temporary overvoltage.

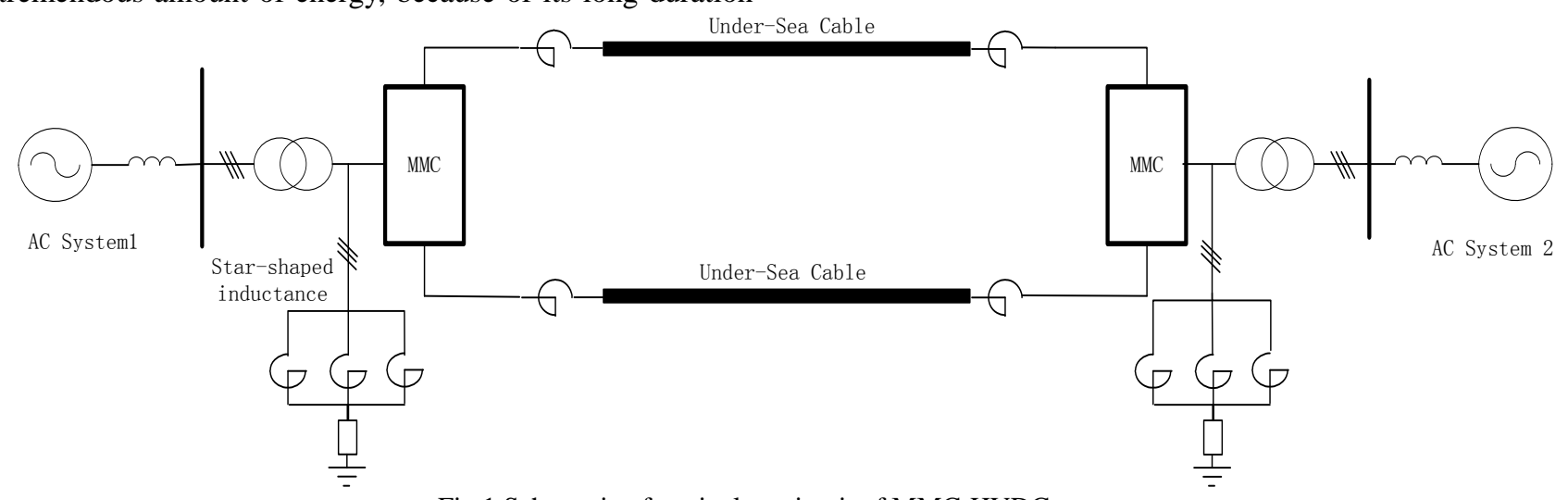

Fig.1 Schematic of equivalent circuit of MMC-HVDC system

The switching overvoltage occurs at the time when fault occurs and the subsequent clearing process. Its duration is very short, with a typical value of a few milliseconds; its magnitude is much higher than the temporary overvoltage, and the surge arresters is adopted to limit it to an acceptable range. As a result, it's necessary to consider all possible faults that would happen in converter stations ${ }^{[10]}$. All the faults can be specified as 3 types, according to their locations:

1. Faults on the AC side of converter station: this paper mainly considers metallic AC bus faults, which are three-phase ground fault (A), two-phase ground fault (B), single-phase ground fault (C) and inter-phase short circuit fault (D).

2. Faults on the DC side and the valve hall of converter station: this paper mainly considers metallic AC bus faults (secondary side of converter transformer) and valve faults, which are three-phase ground fault $(\mathrm{E})$, two-phase ground fault (F), single-phase ground fault (G), inter-phase short circuit fault $(\mathrm{H})$, short circuit fault of valve (I) and ground fault at the top of cascaded sub-modules (J).

3. DC line Fault: which are DC bus ground fault (K), DC line ground fault (L), DC line disconnect fault (M) and inter-polar short circuit of DC lines (N).

\section{SYSTEM SIMULATION PARAMETERS}

A simulation system is built using electromagnetic transient simulation software PSCAD/EMTDC as fig.1, according to Transbay project by SIEMENS and actual situation, main circuit parameters are defined as in tab.1. Under normal operations, converter station 1 serves as slave station, while converter station 2 serving as the master station. The cascaded sub-modules are modulated by the method of Nearest Level Control (NLC). As the MMC-HVDC doesn't have the self-restore ability from DC fault ${ }^{[11]}$, the MMC-HVDC has to block trigger pulse, followed by opening AC breakers to clear DC fault. Assuming trigger pulse for IGBT is blocked $5 \mathrm{~ms}$ after DC fault, followed by opening the AC breakers 95ms later, and this fault clearance strategy is applied in fault $\mathrm{E} \sim \mathrm{N}$ mentioned in chapter 2.B. For AC bus fault A D at AC grid side, fault will be cleared 100ms after happening, and IGBT trigger pules won't be blocked.

Tab.1 Main circuit parameters of the digital model

\begin{tabular}{|c|c|c|c|}
\hline & parameter & values & comments \\
\hline \multirow{4}{*}{$\begin{array}{c}\mathrm{DC} \\
\text { system }\end{array}$} & Rated DC voltage & $\pm 200 \mathrm{kV}$ & \\
\hline & Rated power & $\begin{array}{l}\text { 200MVA/per } \\
\text { pole }\end{array}$ & \\
\hline & Cable length & $80 \mathrm{~km}$ & \\
\hline & Smoothing reactor & $50 \mathrm{mH}$ & \\
\hline \multirow{2}{*}{$\begin{array}{c}\mathrm{AC} \\
\text { system }\end{array}$} & $\begin{array}{c}\text { Voltage, short-circuit } \\
\text { current }\end{array}$ & $220 \mathrm{kV}, 40 \mathrm{kA}$ & \\
\hline & Converter transformer & $220 k V / 208 k V$ & $\begin{array}{c}\text { Leakage reactance } \\
0.12 \mathrm{pu} \\
\text { Y0/D }\end{array}$ \\
\hline \multirow{3}{*}{ converter } & Sub module number & 20 & \multirow{3}{*}{$\begin{array}{c}\text { Accelerating } \\
\text { simulation speed }\end{array}$} \\
\hline & $\begin{array}{l}\text { Capacitance of sub } \\
\text { module }\end{array}$ & $1300 \mu \mathrm{F}$ & \\
\hline & $\begin{array}{c}\text { Rated Capacitance } \\
\text { voltage of sub module }\end{array}$ & $20 \mathrm{kV}$ & \\
\hline
\end{tabular}

\section{THE SURGE ARRESTER CONFIGURATION OF} CONVERTER STATIONS

In the discussion below, voltage at some key points needs to pay special attention, including: 1.voltage of converter transformer on the primary side (1) in Fig.2); 2.voltage of converter transformer on the secondary side (2)in Fig.2); 3.voltage at the bottom of cascaded sub-modules (3) in Fig.2); 4.voltage at the top of cascaded sub-modules (4) in Fig.2); 5.voltage at the DC bus (5) in Fig.2); 6.voltage of bridge reactance (between (2)and(3) in Fig.2); 7.voltage of the cascaded sub-modules (between (3) and (4) in Fig.2); 8.voltage of the smoothing reactors (between (4)and(5) in Fig.2). 


\section{A. ANALYSIS OF ARRESTER CONFIGURATION SCHEME}

Like in classic HVDC, the basic principles for MMC-HVDC converter station arrester arrangement are that: (1) overvoltage generated on the AC side should be limited by the arresters on the AC side; (2) overvoltage generated on the DC side should be limited by the arresters on the DC side; (3) critical components should be directly protected by arresters connected close to them ${ }^{[12]}$. Following these principles, arrester configuration scheme is shown in Fig.2, all key points are directly protected by arresters, and is much simpler than that of classic HVDC. In this scheme, all the critical components are directly protected by the arresters close to them, plus indirect protection from the combination of other arresters.

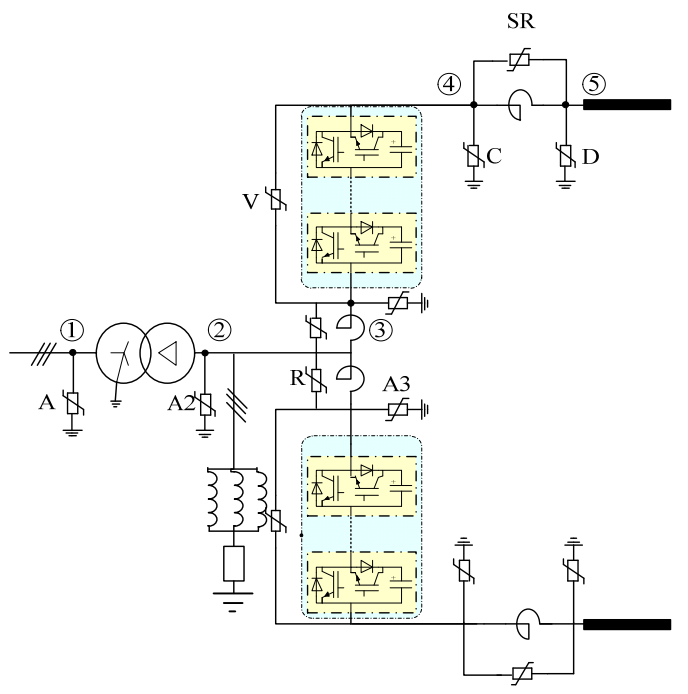

Fig.2 Arrester configuration scheme and some key points in converter station

A total of 8 different arresters are used in this protection scheme:

(a) The AC bus arrester A locates on the primary side of converter transformer, and protects the equipment connecting to AC bus. It needs to be arranged close to converter transformer bushing at the line side, and can directly limit overvoltage both at primary and secondary side of converter transformer. It's must to be pointed out arrester A should be selected carefully with fully consideration of the existed AC arresters in the AC system, and a lower protective level of arrester $\mathrm{A}$ is recommended to avoid energy overload of other existed AC arrester.

(b)The arrester A2 locates on the secondary side of converter transformer, can directly limit the overvoltage generated on the secondary side of converter transformer and serves as a direct protection of the star-shape grounding equipment.

(c)The arrester A3 locates between the bridge reactance and the cascaded sub-modules is an indirect protection of the bridge reactance with arrester $\mathrm{A} 2$ and also an indirect protection of the valve with arrester $\mathrm{C}$.
(d)The arrester $\mathrm{R}$ is in parallel with bridge reactance acting as a direct protection of it, and is an alternative arrester. With this arrester, the rated withstand voltage of bridge reactance can be significantly reduced, but would increase total cost. Given that more severe faults still exist, $\mathrm{R}$ is installed as a conservative choice.

(e)The valve arrester $\mathrm{V}$ direct protects the cascaded sub-modules, since the IGBT module is relatively expensive and important in MMC-HVDC system. Even though there's an indirect protection by the combination of arrester A3 and $\mathrm{C}$, the use of $\mathrm{V}$ will both lower valve specified withstand voltage thus total cost of converter station and also form indirect protections with other arresters.

(f)The arrester $\mathrm{C}$ locates at the top of the cascaded sub-modules protects the corresponding pole from the overvoltage from DC lines.

(g)The arrester D consists of DC line arrester DL and DC bus arrester DB. The overvoltage on DC lines can be limited by it.

(h)The arrester SR is in parallel with smoothing reactor, can limit the most severe overvoltage when reverse polarity transient voltage occurs at both ends of smoothing reactor, but will weaken its ability to suppress lightning overvoltage from the DC lines.

It should be noted that lightning overvoltage could be omitted, because all the DC lines of this project are under-sea cable and the lightning overvoltage from AC line can be suppressed by AC line arresters.

\section{B. DERMINATION OF ARRESTER PARAMETERS}

Given that there's no exclusive guideline in selecting the parameters of MMC-HVDC arresters, the arrester parameters are defined based on chargeability. For DC arresters, chargeability is the ratio of peak value of continuous operation voltage to the reference voltage of the arrester. There's no chargeability for AC arresters in the national standard GB11032-2000<Metal oxide surge arrester without gaps for a.c. systems $>$. In this paper, the chargeability for AC arresters is defined as the ratio of the peak value of maximum continuous operation voltage to the reference voltage of the arrester. The reference voltage of an arrester is the arrester voltage when there's a $1 \mathrm{~mA} \sim 5 \mathrm{~mA}$ current (reference current) passing through. The value of an arrester reference current varies according to its diameter and the column number.

Selecting a reasonable chargeability includes arrester stability, leakage current, equipment insulation level, etc. Small chargeability contributes to a low arrester energy loss under continuous operation and high arrester stability; large chargeability makes a low protective level and a low insulation level ${ }^{[13]}$. For AC arresters, typical chargeability varies from $0.7 \sim 0.8$, while the typical value is $0.8 \sim 1.0$ for DC arresters ${ }^{[14]}$.

After a lot of trials and adjustment, the reference voltages of all the arresters are chosen as in tab.2

Tab2. Reference voltage selection of the arresters

\begin{tabular}{cccc}
\hline Arrester & PCOV $/ \mathrm{kV}$ & Uref $/ \mathrm{kV}$ & chargeability \\
\hline $\mathrm{A}$ & 191 & 233 & 0.82 \\
\hline
\end{tabular}




\begin{tabular}{cccc}
\hline A2 & 189 & 222 & 0.85 \\
A3 & 199 & 228 & 0.87 \\
V & 405 & 420 & 0.96 \\
C & 206 & 258 & 0.80 \\
D & 206 & 258 & 0.80 \\
R & $/$ & 120 & $/$ \\
SR & $/$ & 100 & $/$ \\
\hline
\end{tabular}

IV. THE OVERVOLTAGE AND INSULATION CO-ORDINATION OF CONVERTER STATIONS

\section{A. THE MOST SEVERE OVERVOLTAGE IN ALL FAULTS}

According to fault scanning, the most severe faults are fault G, I, J, K, L. Overvoltage (P.U.) at all the key points (in Fig.2) of these faults are shown in tab.3.

Tab3. Overvoltage at all key points in some most severe faults

\begin{tabular}{ccccccccc}
\hline Fault|Point & (1) & (2) & (3) & (4) & (5) & (6) & (7) & (8) \\
\hline G & 1.14 & 1.88 & 2.17 & 1.74 & 1.77 & 0.88 & 2.71 & 0.78 \\
I & 1.17 & 1.97 & 3.33 & 1.05 & 1.03 & 1.42 & 3.55 & 0.33 \\
J & 1.08 & 2.43 & 2.70 & 2.76 & 2.81 & 1.06 & 2.13 & 1.04 \\
K & 1.10 & 2.77 & 3.02 & 2.74 & 2.83 & 0.96 & 2.09 & 0.62 \\
L & 1.11 & 2.75 & 3.05 & 2.74 & 2.78 & 0.95 & 2.09 & 0.63 \\
\hline
\end{tabular}

\section{B. WITHSTAND VOLTAGE SPECIFICATION OF} CONVERTER STATION EQUIPMENT

According to IEC 60071-5 $5^{[15]}$, co-ordination voltage $\mathrm{U}_{\mathrm{CW}}$ can be obtained from multiplying a co-ordination factor $K_{C}$ to the representative overvoltage $U_{R P}$. For equipment on the DC side, the required withstand voltage must covers ageing of insulation, changes in the arrester characteristics and the dispersion in product quality.

Referring to the classic HVDC project, $\mathrm{U}_{\mathrm{rw}}=\mathrm{K}^{*} \mathrm{U}_{\mathrm{rp}}$ can be used to calculate the required withstand overvoltage. For altitudes up to $1000 \mathrm{~m}$, factor $\mathrm{K}$ is recommended as $\mathrm{K}=115 \% / 120 \% / 125 \%$ (switching/lightning/fast-front).Specif ied switching impulse withstand voltage(SSIWV) of all equipment directly protected by arresters are selected in Tab.4, according to IEC 60071-1 $1^{[12]}$.

Tab4. SIPL and SSIWV of the converter station

\begin{tabular}{cccccc}
\hline Location & Arrester & SIPL/kV & $\mathrm{I}_{\mathrm{CO}} / \mathrm{kA}$ & SSIWV/kV & Margin/\% \\
\hline (1) & $\mathrm{A}$ & 302 & 0.1 & 380 & 26 \\
(2) & $\mathrm{A} 2$ & 313 & 2 & 380 & 21 \\
(3) & $\mathrm{A} 3$ & 371 & 10 & 450 & 21 \\
(4) & $\mathrm{C}$ & 377 & 4 & 450 & 19 \\
(5) & $\mathrm{D}$ & 377 & 4 & 450 & 19 \\
(2)-(3) & $\mathrm{R}$ & 169 & 2 & 250 & 47 \\
(3)-(4) & $\mathrm{V}$ & 627 & 5 & 750 & 20 \\
(4)-(5) & $\mathrm{SR}$ & 149 & 5 & 200 & 34 \\
\hline
\end{tabular}

V. CONCLUSION

(1)Based on the topology of Transbay project, this paper designed a simple arrester configuration scheme, to directly protect critical equipment in converter station.

(2)14 faults are put forward in the calculation of overvoltage and insulation co-ordination. It is found out that the single-phase ground fault in the secondary side of transformer, the short circuit fault of valve, the ground fault on the top of valve and the ground fault on DC bus are 4 most severe faults.

(3)Arrester parameters are determined based on chargeability. The typical value are $0.85 \sim 0.95$ for DC arresters, and around 0.8 for AC arresters.

(4)The SSIWVs of converter station equipment are specified using deterministic method, and the SSIWV of under-sea cable is chosen to be $450 \mathrm{kV}$.

\section{REFERENCE}

[1] GUAN Minyuan, XU Zheng, TU Qingrui, et al. Nearest Level Modulation for Modular Multilevel Converters in HVDC Transmission[J]. Automation of Electric Power Systems, 2010, 34(2): 48-52.

[2] TU Qingrui, XU Zheng, GUAN Minyuan, et al. Design of Circulating Current Suppressing Controller for Modular Multilevel Converter[J]. Automation of Electric Power Systems, 2010, 34(18): 57-61, 83.

[3] Westerweller T, Friedrich K, Armonies U, et al. Trans bay cable world's first HVDC system using multilevel voltage sourced converter[C]// Proceedings of CIGRE. Paris, France: CIGRE, 2010.

[4] DONG Yunlong, BAO Hailong, TIAN Jie, HU Zhaoqing, ZHANG Jianfeng, LIU Jun.Control and Protection System for VSC-HVDC[J]. Automation of Electric Power Systems, 2010, 35(19): 89-92.

[5] GUAN Min-yuan, XU Zheng. Modeling and Control of Modular Multilevel Converter in HVDC Transmission[J]. Automation of Electric Power Systems, 2010, 34(19): 64-68.

[6] Gnanarathna U N, Gole A M, Jayasinghe R P. Efficient modeling of modular multilevel HVDC converters on electromagnetic transient simulation programs[J]. IEEE Transactions on Power Delivery, 2011, 26(1): 316-324.

[7] Tu Q R, Xu Z. Impact of sampling frequency on harmonic distortion for modular multilevel converter[J]. IEEE Transactions on Power Delivery, 2011, 26(1): 298-306.

[8] DING Guan-jun, TANG Guang-fu, DING Ming, et al. Topology mechanism and modulation scheme of a new multilevel voltage source converter modular[J]. Proceedings of the CSEE, 2009, 29(36): 1-8.

[9] WANG Shan-shan, ZHOU Xiao-xin, TANG Guang-fu, et al. Influence of AC system strength on operating characteristics of MMC-HVDC system[J]. Power System Technology, 2011, 35(2): 17-24.

[10] NIE Dingzhen, MA Weimin, ZHENG Jin. Insulation Coordination for 士 $800 \mathrm{kV}$ UHVDC Converter Stations. High Voltage Engineering, 2006, 32(9): 75-79.

[11] ZHAO Chengyong, CHEN Xiaofang, CAO Chungang, et al. Control and Protection Strategies for MMC-HVDC under DC Faults[J]. Automation of Electric Power System, 2011, 35(23): 82-87.

[12] IEC TS60071-1, Insulation co-ordination-Part 1: Definitions, principles and rules[s], 2006.

[13] ZHOU Peihong, XIU Muhong, GU Dingxie, DAI Min, LOU Ying. Study on Overvoltage Protection and Insulation Coordination for \pm 800 kV HVDC Transmission System[J]. High Voltage Engineering, 2006, 32(12): 125-132.

[14] Q/GDW 144-2006, Guide for overvoltage protection and insulation coordination of $\pm 800 \mathrm{kV}$ UHVDC converter station[S]. Beijing: China Electric Power Press, 2006.

[15] IEC TS60071 - 5, Insulation co-ordination-Part 5: Procedures for high-voltage direct current(HVDC)converter stations[s], 2002. 